\title{
Implementation of the Lisbon Strategy Targets at the Regional Level in the EU and Slovenia
}

\author{
UDK: 338.1:061.1EU(045)
}

\author{
Aleksander Aristovnik \\ University of Ljubljana, Faculty of Administration \\ aleksander.aristovnik@fu.uni-lj.si \\ Andrej Pungartnik \\ University of Ljubljana, Faculty of Economics \\ endrej.pungartnik@ef.uni-lj.si
}

\begin{abstract}
In 2000, the European Union set itself a target in the Lisbon Strategy to become the most dynamic, competitive and knowledge-based economy in the world in ten years, whereas during the mid-term review, which was held five years later, it redefined its two main objectives: creation of new and better jobs and achievement of stronger, lasting economic growth. This paper aims to study the current situation in the European Union and Slovenia regarding the implementation of the targets of the renewed Lisbon Strategy. The analysis focuses on establishing at what stage the EU is in the attainment of its goals and how successfully it has implemented the strategy at the regional level of the EU Member States. The basic tools in the analysis included the time-distance monitoring method and a presentation of the time lead or lag in the implementation of the selected Lisbon Strategy targets at the NUTS 2 regional level of the enlarged EU and Slovenia.
\end{abstract}

Key words: Lisbon Strategy, cohesion policy, NUTS 2 regions, Slovenia, time distance

JEL: C10, R10, O10, 052

\section{Introduction}

From its beginnings, the European Union (EU) has strived to build up a competitive and progressive economy which creates jobs and strikes the right balance between economic efficiency and social justice. By implementing its 


\section{Aleksander Aristovnik, Andrej Pungartnik Implementation of the Lisbon Strategy Targets at the Regional Level in the EU and Slovenia}

structural and cohesion policies through Structural Funds, the Cohesion Fund and other instruments, the Union has over several decades strengthened social and economic cohesion, whereas by adopting the Lisbon Strategy it undertook to pursue the objectives in an even more structured and ambitious manner.

With the passing of time the Lisbon Strategy has increasingly impacted the formulation and implementation of policies at the levels of the EU and member states. The implementation of these policies contributes to higher economic growth at the EU level and, through financial mechanisms of the Structural Funds and the Cohesion Fund, it boosts economic growth in the member states, especially the new ones, which is in turn reflected in the bridging of the development gaps between EU countries and regions, resulting in real convergence.

The reform package which was agreed upon in Lisbon has seen some progress at the national and European levels; however, Europe still lags considerably behind the plan. Moreover, the Union entered the new Lisbon cycle as the global growth was slowing down due to the serious financial crisis spreading all over the world. Although the recession will make achievement of the Lisbon targets very difficult, it is still important to continue implementing the Strategy in these times of crisis as this is the only way to mitigate the effects of the recession. It is of the utmost importance to strengthen the efficient implementation of the strategy, part of which includes an evaluation of the adopted measures and their results. The time-distance method, as used in this analysis, can due to its clarity and simplicity make an important link in the evaluation chain by clearly illustrating the incongruence between the actual state of affairs and the set Lisbon Strategy targets at the regional and national levels. The article aims to analyse the current state of affairs in the European Union and Slovenia in the course of attaining the Lisbon Strategy targets, as well as to demonstrate in concrete terms, using an application designed by the Socio-economic Indicators Center ${ }^{\mathbf{1}}$, the time leads or lags in the attainment of individual targets, expressed in time distances at the level of the NUTS 2 regions of the EU and Slovenia.

1 SICENTER is a private, non-profit research institution. Its activities focus on research and consultancy in the field of the analysis of economic and social indicators at various levels of aggregation, with an application to economics, politics, business and statistics. The principal researcher is Prof. Pavle Sicherl, PhD. (Center za socialne indikatorje - SICENTER, 2008).

2 The term NUTS (French: Nomenclature des unités territoriales statistiques) stands for the Nomenclature of Territorial Units for Statistics or the common European statistical classification of territorial units. This classification was established by Eurostat to provide for a comprehensive and consistent subdivision of territorial units as required for collecting, developing 


\section{Aleksander Aristovnik, Andrej Pungartnik \\ Implementation of the Lisbon Strategy Targets at the Regional Level in the EU and Slovenia}

\section{The Lisbon Strategy}

In the face of the EU's diminishing competitive edge relative to the United States of America and the rapidly developing Asian countries, the heads of states and governments of the Union decided at the spring 2000 session of the European Council that the EU needed a long-term strategy. Europe set itself a strategic target of becoming the most dynamic, competitive, knowledge-based economy in the world which creates new and better-quality jobs and fosters continuous economic growth along with a greater social cohesion, as well as an economy which respects and protects the environment (Kok, 2004, p. 8). The Strategy was supplemented at the spring 2001 session of the European Council in Stockholm and at the 2002 session of the European Council in Barcelona. During the Swedish Presidency of the EU an environmental dimension was embedded in the Strategy, whereas the Spanish Presidency put a greater emphasis on the social dimension and investments in research and development (Government Office of the Republic of Slovenia for European Affairs, 2008).

In view of unsatisfactory progress and the even bigger gap in the growth potential between Europe and other economies, in February 2005 the European Commission proposed an amendment of the Lisbon Strategy to the member states. The revised version redefined the priorities and the methods for attaining them, while putting growth and employment on top of all Lisbon Strategy targets. The reform of the Lisbon Strategy also encompassed the approval of the cohesion policy as the key Community instrument contributing to implementation of the strategy for growth and jobs. Besides maintaining social cohesion, the European Council also included among the key priorities for attainment of the Lisbon targets investing in knowledge and innovations, making the business environment more attractive to investors and workers as well as creating more and better quality jobs (A New Start for the Lisbon Strategy, 2005, p. 7).

Through the reform that the Commission proposed, the European cohesion policy thus became one of the most important Community policies aimed at realising the Union's agenda for growth and jobs. After the EU's enlargement to

and harmonizing regional statistics in the European Union. As the NUTS classification is based on a hierarchical subdivision, the territories of the countries are divided into three hierarchical levels: NUTS 1, NUTS 2 and NUTS 3, where the territories of the countries are divided into NUTS units on the basis of the normative criteria (population size) laid down in the NUTS Regulation (NUTS, 2008). 
Aleksander Aristovnik, Andrej Pungartnik

Implementation of the Lisbon Strategy Targets

at the Regional Level in the EU and Slovenia

27 member states and a dramatic increase in the differences between individual members and regions in terms of development, the correlation among the attainment of both targets of economic growth and cohesion grew even stronger at the EU level. The EU as a whole will not be able to achieve higher economic growth rates as it does now if the new members fail to steadily generate economic growth that is substantially higher than the Union's average. A high economic growth in the less developed EU regions is important for the concurrent attainment of both targets, the real convergence of the less developed Community regions and faster economic growth in the EU as a whole. In this context, it is only logical that, in the medium-term period between 2007 and 2013, the EU should allocate the cohesion funds mainly for the purposes ensuring sustainable economic growth, the competitiveness of the economy and employment such as envisaged in the revised Lisbon Strategy (National Strategic Reference Framework 2007-2013, 2007, p. 3).

\section{Effects of the cohesion policy at the level of NUTS 2 EU regions}

One of the main targets of the cohesion policy is to reduce economic and social differences in development between European regions. Those regions which lag behind in development terms should remain at the focus of the policy which must cover the entire EU territory, given that the goal of the cohesion policy is to stimulate European regions' development potential. Accurate measurement of the effects of the cohesion policy is difficult for several reasons. Jones $(2001$, p. 247) mentions the following three main reasons: first, all of the effects of certain programs and projects can only be seen in the long run; second, both regional and national economies are influenced by a series of factors whose influence is difficult to define precisely; and, third there is a problem of separating the effect of the EU policy from the effects of national regional policies. Despite some serious efforts invested by the EU, there are still large differences between the member states and their regions in terms of GDP per capita. In the last few years, the convergence of European regions has been fairly strong, thus reducing 
Aleksander Aristovnik, Andrej Pungartnik

Implementation of the Lisbon Strategy Targets at the Regional Level in the EU and Slovenia

the discrepancies in terms of GDP per capita. ${ }^{3}$ This trend is mainly the result of the improvement in the least successful regions, whereas the diminishing differences can be ascribed to slower growth in GDP in the most developed countries. The analysis below was made at the NUTS 2 EU region level.

Table 1: The most and the least developed EU regions in terms of GDP p.c. in the 2000-2005 period

\begin{tabular}{|c|c|c|c|c|}
\hline \multirow{2}{*}{ Regions } & \multicolumn{2}{|c|}{ EU-15 } & \multicolumn{2}{|c|}{ EU-27 } \\
\hline & 2000 & 2005 & 2000 & 2005 \\
\hline $10 \%+$ & 191.6 & 187.7 & 184.7 & 173.8 \\
\hline $10 \%-$ & 67.6 & 70.0 & 30.9 & 36.7 \\
\hline Coefficient 1 & 2.8 & 2.7 & 6.0 & 4.7 \\
\hline $25 \%+$ & 160.0 & 156.0 & 150.9 & 149.9 \\
\hline $25 \%-$ & 79.1 & 79.8 & 47.9 & 52.8 \\
\hline Coefficient 2 & 2.0 & 1.95 & 3.5 & 2.8 \\
\hline
\end{tabular}

Note: Data refer to GDP per capita measured by purchasing power parity; the value of GDP is expressed as \% of the average GDP of the European Union; $10 \%+$ and $25 \%+$ refer to the regions with the highest GDP per capita, accounting for $10 \%$ and $25 \%$ of the total EU population, respectively; $10 \%-$ and $25 \%$ - refer to the regions with the lowest GDP per capita, accounting for $10 \%$ and $25 \%$ of the total EU population, respectively. Coefficient 1 is calculated as $10 \%+/ 10 \%$; and coefficient 2 as $25 \%+/ 25 \%$ -

Source: Eurostat; own calculations.

Table 1 shows that, in 2000, the GDP per capita of the richest regions, accounting for $10 \%$ of the EU-15 population, was nearly $92 \%$ higher than the EU average, whereas the GDP per capita of the poorest regions, accounting for $10 \%$ of the EU-15 population, was more than $32 \%$ lower than the EU average.

3 What is meant is real convergence, which means approximation to the economic development level as is usually represented by the indicator of gross domestic product per capita (measured by the purchasing power parity). Analysing real convergence between the states (regions) with this indicator actually means assessing whether the GDP per capita of a certain country, region or group of countries approximates the average value of this indicator for all compared countries (regions) (Martín, 2001, p. 7). 


\section{Aleksander Aristovnik, Andrej Pungartnik \\ Implementation of the Lisbon Strategy Targets at the Regional Level in the EU and Slovenia}

Expressed as a coefficient, the GDP of the richest regions $(10 \%+)$ in 2000 was 2.8 times higher than that of the poorest regions (10\%-). The 2005 coefficient was 2.7, meaning that the differences between the richest and poorest regions have slightly decreased in the studied period but no considerable improvement was observed, which is why the cohesion policy was reformed and the strategy revised.

The table also shows that the differences between the EU regions markedly increased after the new members joined the Union. This demonstrates the size of the change caused by the enlargement of the EU to 27 states in 2000 (including the 10 candidate countries which joined the EU in 2004 plus Bulgaria and Romania) as well as its effect on the coefficients. It has been established that, in 2000, the GDP per capita of the poorest regions, accounting for $10 \%$ of the EU-27 population, was nearly $70 \%$ below the European average. In 2000, the coefficient was 6.0, meaning that the GDP of the richest regions $(10 \%+$ of EU-27) was six times higher than that of the poorest regions (10\%-EU-27). The differences between the regions further increased after the accession of the new members; however, in the five-year period the coefficient dropped to 4.7 and demonstrated that the poorest regions at the EU-27 level took a step ahead and that the drop in the coefficient was also due to the lower average GDP per capita in the most developed regions compared to the EU average. Of course, the differences between the most and the least developed regions are still extremely large and it will take a long time before the least developed regions approximate the EU average.

It is also interesting to establish Slovenia's place among the most and least developed EU regions. As of 2009 the territory of the Republic of Slovenia was divided into two cohesion regions at the NUTS 2 level - Eastern Slovenia and Western Slovenia. At the NUTS 1 level Slovenia is still considered as a whole, whereas at the NUTS 3 level it is divided into 12 statistical regions, as it was before.

Table 2 shows that in 2000 Slovenia's GDP per capita was lower than the EU-27 average by a good $20 \%$, and in 2005 by a good $12 \%$. Very large differences are observed at the NUTS 2 region level, with Western Slovenia already exceeding the Union's average development level in 2005 and Eastern Slovenia considerably lagging behind it. Large differences in terms of development by GDP per capita also existed within Slovenia, and the gap between the regions kept increasing in the abovementioned period. Consequently, Slovenia still has much to do in the area of Eastern Slovenia. 
Aleksander Aristovnik, Andrej Pungartnik

Implementation of the Lisbon Strategy Targets at the Regional Level in the EU and Slovenia

Table 2: Slovenia's development at the NUTS 2 level in terms of GDP p.c. in the 2000-2005 period (EU-27=100)

\begin{tabular}{|l|c|c|}
\hline \multirow{2}{*}{} & \multicolumn{2}{|c|}{ Slovenia } \\
\cline { 2 - 3 } & 2000 & 2005 \\
\hline Slovenia & 79.8 & 87.4 \\
\hline East Slovenia & 67.3 & 72.5 \\
\hline West Slovenia & 94.5 & 104.8 \\
\hline
\end{tabular}

Note: The data refer to GDP per capita measured by purchasing power parity; Eastern Slovenia: Pomurska, Podravska, Koroška, Savinjska, Zasavska, Spodnjeposavska, South-Eastern Slovenia and Notranjsko-kraška; Western Slovenia: Central Slovenia, Gorenjska, Goriška and Obalno-kraška.

Source: Eurostat; own calculations.

The above shows that the accession of the new countries rendered attainment of the Lisbon targets even more difficult and that there are big differences between the regions at the EU level. In the period under scrutiny, most of these least developed regions were not parts of the EU; however, the purpose of the analysis is to highlight the enormous differences between the regions in development terms and to quantify the lag of the least developed regions behind the most developed ones. The main task of the cohesion policy is to decrease disparities between the EU regions; the present results show that strenuous efforts will have to be invested in reducing the differences so as to enable the least developed regions to approximate welfare. The lags behind the Lisbon targets at the NUTS 2 region level were established using the time distance calculation method.

\section{Calculation of time distances and leads/lags in meeting the Lisbon Strategy targets}

\subsection{Time distance}

In general, time distance is the distance in time between two events. S-time distance is a special category of time distance which is defined for a specified level 


\section{Aleksander Aristovnik, Andrej Pungartnik \\ Implementation of the Lisbon Strategy Targets at the Regional Level in the EU and Slovenia}

of a variable (indicator). In contrast to statistical measures defined by a specific time unit, the S-time distance is defined for a specific level of variable and measures the distance in time between points when the two units being compared reach a given level of the observed variable. The specified distance in time (e.g. the number of years, months, days etc.) is used as a dynamic (temporal) measure of the disparity between the two observed units, in the same way that the difference (absolute or relative) at a given point in time is used as a static measure of disparity between the observed units (Sicherl, 2003, p. 188).

When two functions or series with time subscripts are compared for a specified level of variable $X$, the difference in time between the obtained values $t_{1}$ and $t_{2}$ equals the time distance between the two units for a given level of variable $X$. For a given level of variable $X_{L} X_{L}=X_{i}\left(t_{i}\right)=X_{j}\left(t_{j}\right)$, the S-time distance between the (i) and (j) units is defined as:

$$
S_{i j}\left(X_{L}\right)=\Delta T\left(X_{L}\right)=t_{i}\left(X_{L}\right)-t_{j}\left(X_{L}\right)
$$

where $T$ is defined by $X_{L}$. In a particular case, $T$ can be a function of the level of variable $X_{L}$, whereas as a rule one may expect to obtain several values for time $T$ when the given level of the variable was achieved at several points in time or time intervals. In such cases the S-time distance becomes a vector whose elements are also linked with time, besides the level of variable $X_{L}$. Generally speaking, the S-time distance between the (i) and (j) units is defined by the level of variable $X_{L}$ in a given time $(t)$. The following three subscripts are required to characterize the specific value of the S-time distance: (1 and 2) two units which are used to measure the time distance and (3) the level of variable $X$ (similarly to using the time subscript for characterising statistical measures of differences). As a rule, a fourth subscript is required to indicate the point in time defining the time distance $\left(T_{1}, T_{2} \ldots T_{n}\right)$. The sign of the time distance used for comparing two units is important to distinguish whether we are dealing with a time lead (-) or lag (+) (in a statistical sense and not as a functional relationship):

$$
\operatorname{Sij}(X L)=-S j i(X L)
$$

\footnotetext{
4 More details about S-time distance see also Granger (1997, 2003).
} 


\section{Aleksander Aristovnik, Andrej Pungartnik \\ Implementation of the Lisbon Strategy Targets at the Regional Level in the EU and Slovenia}

To calculate the S-time distance at macro level, two time series are needed: the time series of the actual values of indicator and the time series of the anticipated target values (line to target). Time distance is therefore the distance between the actual time and the time on the line to the target for each actual value of the variable (Sicherl, 2008, p. 2.):

$S\left(X_{t}\right)=$ actual time $t-$ time on the target line $T$ for each actual value of variable $X_{t}$

$$
S\left(X_{t}\right)=t\left(X_{t}\right)-T\left(X_{t}\right)
$$

The introduction of time distance in the analysis of differences is intended to complement, rather than replace, the conventional static methods and measurements as well as to broaden the overall theoretical and methodological approach. The application of the time-distance concept and its operationalisation using the S-time-distance statistical measure are instruments complementing the existing methods of analysis, thus enhancing the understanding of the problem and improving two areas, conceptual and analytical. An advantage of the S-time distance lies in the fact that the latter is expressed in time units and is thus understandable by everyone, while another advantage is its ability to leave all previous methods and results (not necessarily the conclusions) unchanged since the time distance adds a new dimension rather than replaces other perspectives (Sicherl, 2003, p. 189).

\subsection{Calculation of the lag/lead in meeting the Lisbon Strategy targets at the NUTS 2 region level}

Another view of the degree of the Lisbon Strategy's implementation in terms of the set EU or national targets was offered by the Socio-economic Indicators Center. It designed a web application enabling a simplified calculation of time distances and leads/lags in meeting the targets, based on which the following analysis was made. The application uses the S-time distance (expressed as time units) for an example of Lisbon targets at the regional level for the EU and Slovenia. It was established - for a given value in a given year when this value would expectedly be attained on the line to target, whereas the time distance expressed a lead/lag in time with respect to the line to target. 


\section{Aleksander Aristovnik, Andrej Pungartnik Implementation of the Lisbon Strategy Targets at the Regional Level in the EU and Slovenia}

In the analysis the average time distance for the most and the least developed NUTS 2 regions was calculated at the levels of the EU-27 and Slovenia. It is again true that the most developed regions include those with the highest GDP per capita which together account for 10\% of the EU-27 population, whereas the least developed regions are those recording the lowest GDP per capita and accounting for $10 \%$ of the EU-27 population. It should be noted that, due to the lack of data at the regional level, the measurement of time distance for individual indicators is made impossible or very difficult. It is thus, for example, impossible to follow the target of the share of GDP allocated to research and development which is one of the fundamental Lisbon targets; however, distances have been calculated for the targets of a 70\% employment rate in the EU and 3\% average annual growth in the EU's GDP by 2010. It should also be emphasised that when data for a specific region, which in terms of (under)development belongs to the $10 \%$ of the most (least) developed regions at the EU-27 level, were not available, such a region was replaced by the next region in the row for which data were available.

\subsubsection{Lisbon targets at the NUTS 2 region level: a $70 \%$ employment rate in the European Union by 2010}

The most developed regions $(10 \%+)$ mainly include regions from older EU member states such as Germany, England, Belgium and the Netherlands, whereas only two regions belong to the new members, namely Prague and Bratislava. The average employment rate of the most developed regions was $68.5 \%$ already in 2000 and was thus very close to the target value; after a slight decrease up until 2004 it again recorded a positive trend in the last two analysed years. This upturn in 2005 and 2006 positively affected the time distance as, in the last analysed year, it was only 2.5 years. The dark columns in the figures showing time distances denote the years in which the actual indicator value was lower than the initial 2000 indicator value.

A completely different picture is seen with the least developed regions, mostly from Bulgaria, Romania and Poland, which have the lowest GDP per capita and together account for $10 \%$ of the EU-27 population. In 2000 their average employment rate was slightly less than $56.9 \%$ and this value was not achieved again in the following six years. In the period under consideration, the time distance constantly increased and equaled 6 years in the last analysed year. 
Aleksander Aristovnik, Andrej Pungartnik Implementation of the Lisbon Strategy Targets at the Regional Level in the EU and Slovenia

Figure 1: Time distance of the 10\%+ regions of the EU-27 in meeting the target of a $70 \%$ employment rate in the EU by 2010

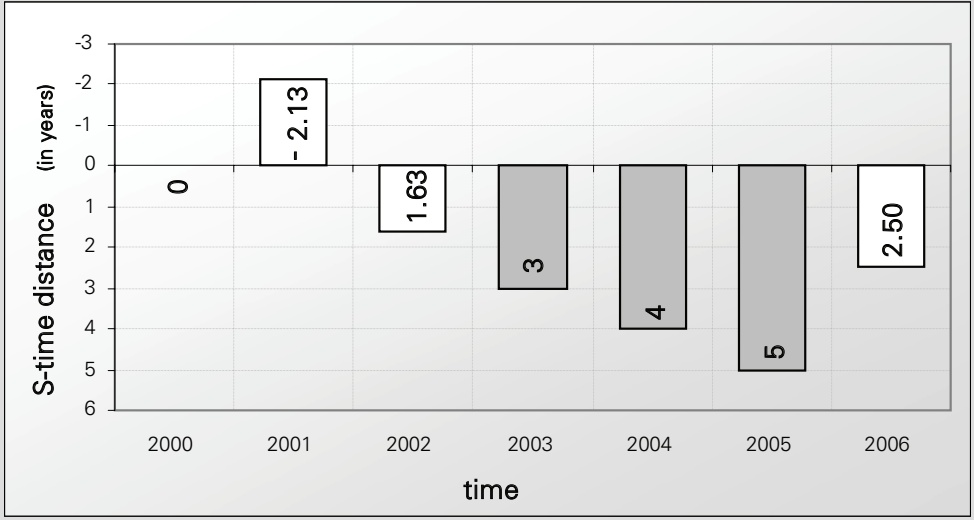

Legend: (-) time lead (ahead of the line to target); time lag (behind the line to target) Source: Eurostat; own calculations.

Figure 2: Time distance of the $10 \%$ - regions of the EU-27 in meeting the target of a $70 \%$ employment rate in the EU by 2010

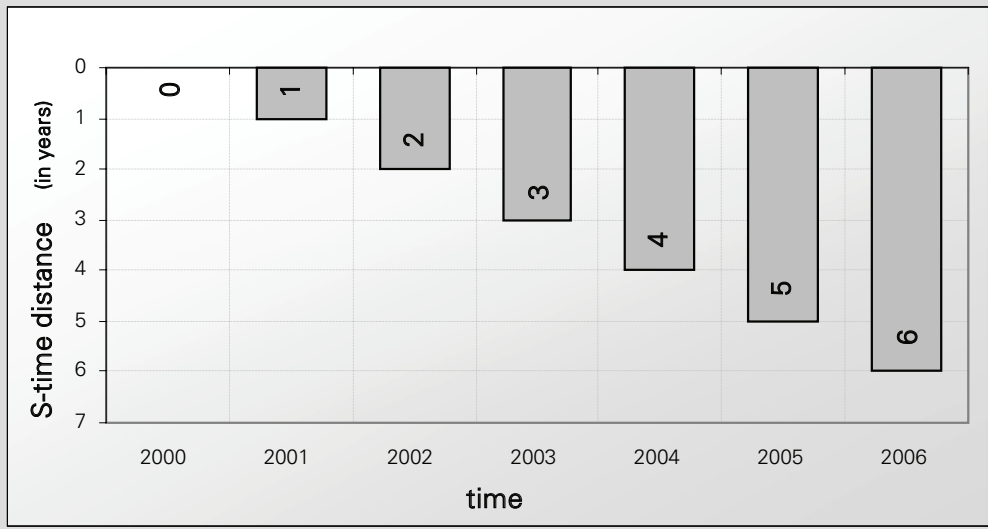

Legend: (-) time lead (ahead of the line to target); time lag (behind the line to target) Source: Eurostat; own calculations. 
Aleksander Aristovnik, Andrej Pungartnik

Implementation of the Lisbon Strategy Targets

at the Regional Level in the EU and Slovenia

\subsubsection{Lisbon targets at the NUTS 2 region level: average 3\% annual growth in European Union GDP by 2010}

The same as for the countries, it is also expected for the regions that the less developed regions would grow faster than the more developed ones because only this generates convergence and decreases the development gap. Thus, negative time distances are expected for the least developed regions i.e. the time lead ahead of the target values, whereas for the most developed regions time lags and positive distances are expected.

Figure 3: Time distance of the 10\%+ regions of the EU-27 in meeting the target of average 3\% annual growth in EU GDP

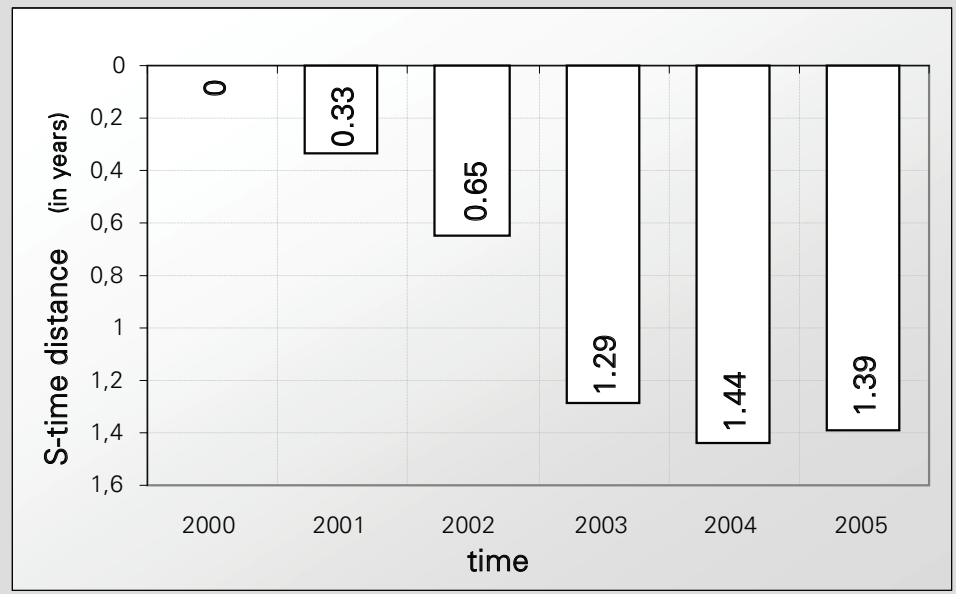

Legend: (-) time lead (ahead of the line to target); time lag (behind the line to target) Source: Eurostat; own calculations.

Since the very start of the Lisbon Strategy's implementation, the average annual growth in the most developed regions $(10 \%+)$ lagged behind the target values, whereas Figure 3 shows that, in the last two analysed years (the last captured year is 2005, due to missing data), the lag leveled off at about 1.4 years. In 2005, the time distance was 1.39 years. 


\section{Aleksander Aristovnik, Andrej Pungartnik \\ Implementation of the Lisbon Strategy Targets at the Regional Level in the EU and Slovenia}

A different picture emerges concerning attainment of the target of average $3 \%$ annual growth of GDP for the least developed regions $(10 \%-)$, as the average rate lags behind or leads ahead of the target values. There was a small lag in the first two years, although as of 2003 the time distance was negative which means a lead ahead of the target value. In 2005 the distance slightly decreased compared to the year before, but the lead was still 1.25 years.

Figure 4: Time distance of the 10\%- regions of the EU-27 in meeting the target of average $3 \%$ annual growth in EU GDP

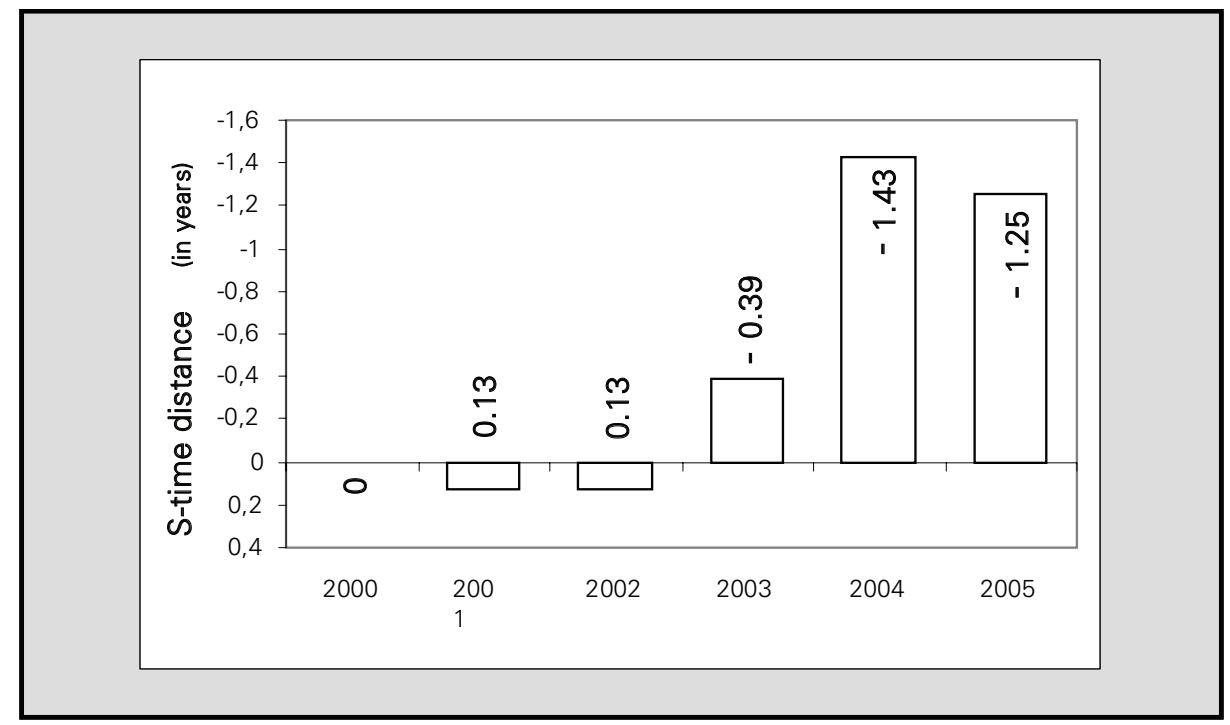

Legend: (-) time lead (ahead of the line to target); time lag (behind the line to target)

Source: Eurostat; own calculations.

It is reasonable to compare the summarised results of the analysed targets (Table 3 ) with the results at the EU-15 level as this means that the analysis will only include those regions which were parts of the EU throughout the studied period. Considering that, at the levels of both the EU-27 and the EU-15, the most developed regions mainly include those from the group of 15, no major differences were expected in the results of the most developed regions, which was also confirmed by the time distances. A different situation can be observed with the least developed regions since it is mainly the regions from the new members (Romania, Bulgaria and Poland) that fall within the $10 \%$ of the least developed regions at the EU-27 level, whereas at the EU-15 level the bulk of such regions belong to the Mediterranean countries (Greece, Italy, Spain and France). In terms of the target of a 70\% employment rate by 2010, the time distance in the 10\%-regions of the EU-27 and EU-15 in 


\section{Aleksander Aristovnik, Andrej Pungartnik Implementation of the Lisbon Strategy Targets at the Regional Level in the EU and Slovenia}

2006 was 6.0 and 4.57 years, respectively. The employment rates in the least developed regions in the new member states were very low and did not increase which only added to the lag behind the Lisbon target, whereas at the EU-15 level small growth was observed but there was still a lag behind the target rate and the distance grew over the analysed period. The data show considerable differences between the most and the least developed countries in terms of employment, which is also evidenced by the differences in time distances. Nevertheless, the trend in the least developed regions of the new member states raises concerns since, due to the declining employment rates in the analysed period, the time distances and consequently the lags behind the Lisbon target soar. The regions where the biggest lags behind the target of a 70\% employment rate by 2010 were recorded at the EU-27 level include the Bulgarian, Hungarian, Romanian and Polish regions which are, as expected, at the very bottom. As far as the EU-15 is concerned, the bottom-level regions include the French overseas departments and the Greek islands, which is mostly due to their geographical remoteness, as well as the regions of southern Spain, Italy and eastern Germany. The regions where the biggest leads were recorded include those from the most developed countries such as England (London, Berkshire, Bucks and Oxfordshire), Austria (Salzburg and Vienna) and Sweden (Stockholm), whereas of the analysed regions of the new member states only Bratislava and Prague were included.

Table 3: Time distances of the most $(10 \%+)$ and the least $(10 \%-)$ developed regions (NUTS 2) at the levels of the EU-27 and EU-15 in meeting the Lisbon Strategy targets

\begin{tabular}{|lccccccc|}
\hline & \multicolumn{7}{c|}{ S-time distance (in years) } \\
\hline Targets & 2000 & 2001 & 2002 & 2003 & 2004 & 2005 & 2006 \\
\hline Target 1 & & & & & & & \\
\hline $10 \%+$ regions EU-27 & 0 & -2.13 & 1.63 & 3 & 4 & 5 & 2.5 \\
$10 \%$ - regions EU-27 & 0 & 1 & 2 & 3 & 4 & 5 & 6 \\
$10 \%+$ regions EU-15 & 0 & -3.36 & 1.23 & 3 & 4 & 5 & 3.32 \\
$10 \%$ - regions EU-15 & 0 & 0.95 & 1.57 & 2.38 & 2.97 & 3.88 & 4.57 \\
\hline Target 2 & & & & & & & \\
\hline $10 \%+$ regions EU-27 & 0 & 0.33 & 0.65 & 1.29 & 1.44 & 1.39 & N/A \\
$10 \%$ - regions EU-27 & 0 & 0.13 & 0.13 & -0.39 & -1.43 & -1.25 & N/A \\
$10 \%+$ regions EU-15 & 0 & 0.44 & 0.86 & 1.56 & 1.79 & 2.03 & N/A \\
$10 \%$ - regions EU-15 & 0 & -0.20 & 0.39 & 0.70 & 1.07 & 1.80 & N/A \\
\hline
\end{tabular}

Legend: Target 1: 70\% employment rate in the EU by 2010; Target 2: average $3 \%$ annual growth in EU GDP; N/A: not applicable

Source: Eurostat; own calculations. 


\section{Aleksander Aristovnik, Andrej Pungartnik \\ Implementation of the Lisbon Strategy Targets at the Regional Level in the EU and Slovenia}

The attainment of the target of average $3 \%$ annual GDP growth was examined only for the 2000-2005 period due to a lack of data. No major differences were established between the time distances of the most developed regions at the EU-27 and EU-15 levels. At both levels, a lag behind the target was identified which kept increasing over the five-year period. Given that the group of $10 \%+$ regions includes the most developed ones, it is understandable that these achieve the targeted average 3\% annual growth in GDP with difficulty as their GDP per capita is already at a very high level and this hinders high average growth rates. On the other hand, the time distance of the regions with the lowest GDP per capita, together accounting for $10 \%$ of the EU-27 population, is negative which translates as a time lead ahead of the line to target. In 2005, the lead was 1.25 years. The EU-15 level shows a different picture as the least developed regions lag behind the line to target, with the 2005 lag equaling 1.8 years. These differences are understandable considering that the $10 \%$ - regions of the EU-27 are much less developed than the least developed regions at the EU-15 level, because the least developed EU-27 regions have great growth potential and their attainment of high average annual GDP growth is easier. The fastest growing regions often include major urban areas and regional capitals (London, Luxembourg, Prague and Bratislava), whereas high growth rates were also observed in the regions with a very low GDP per capita such as, for example, the Bulgarian region of Yugozapaden, the Romanian region of Bucuresti-lefov etc. On the other hand, low growth rates and thus lags behind the targeted average 3\% annual GDP growth are mainly characteristic of the regions with a high GDP per capita in France, Germany, Italy, Finland, Sweden and Denmark.

\subsubsection{Lisbon target for Slovenia: a 70\% employment rate by $\mathbf{2 0 1 0}$}

It is interesting to compare the results of the time distances at the European regional level with those of Slovenia. Yet it should be stressed that, due to a lack of employment rate data for some member states at the NUTS 2 level, the analysis for Slovenia was only made at the level of the entire state. As regards the targeted $70 \%$ employment rate by 2010 , it was established that the time lags behind the target values were much smaller than the time distances in the most and the least developed regions of the EU-27 and EU-15.

In 2006 a slightly larger lag was observed compared to previous years, but it still equaled only 0.59 of a year (Figure 5) which is much better than the time distances at the level of the NUTS 2 EU regions compared to both the 
Aleksander Aristovnik, Andrej Pungartnik Implementation of the Lisbon Strategy Targets at the Regional Level in the EU and Slovenia

most developed regions and the least developed regions where lags are expected to be much bigger.

Figure 5: Time distance of Slovenia in meeting the target of a $70 \%$ employment rate by 2010

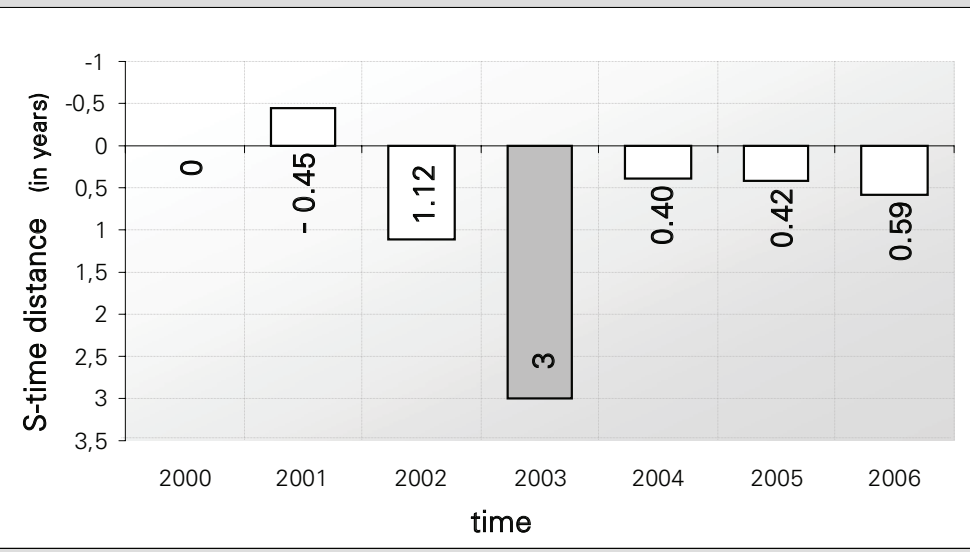

Legend: (-) time lead (ahead of the line to target); time lag (behind the line to target) Source: Eurostat; own calculations.

\subsubsection{Lisbon target for Slovenia: average 3\% annual GDP growth by 2010}

In terms of the targeted 3\% average annual growth of GDP, Slovenia as a new, young member state achieved good results compared to the EU average as they approximate those of the least developed regions at the EU-27 level. From the very beginning, the actual values exceeded the targeted ones, as was also reflected in the time-distance results (Figure 6). In 2006, Slovenia recorded a nearly two-year (1.97) time lead which increased over the last three studied years. 
Aleksander Aristovnik, Andrej Pungartnik

Implementation of the Lisbon Strategy Targets at the Regional Level in the EU and Slovenia

Figure 6: Time distance of Slovenia in meeting the target of average $3 \%$ annual GDP growth

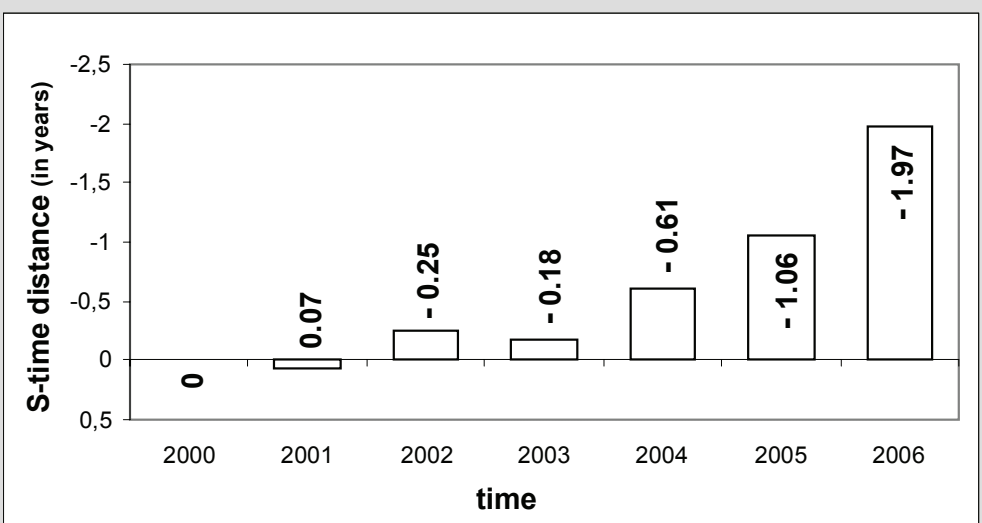

Legend: (-) time lead (ahead of the line to target); time lag (behind the line to target) Source: Eurostat; own calculations.

A look at the attainment of this target at the NUTS 2 level is also interesting. The time distance for Western Slovenia constantly decreased throughout the studied period, which means that the time lead ahead of the line to target increased. In 2005, the lead was 1.47 years.

Figure 7: Time distance of Western Slovenia in meeting the target of average $3 \%$ annual GDP growth

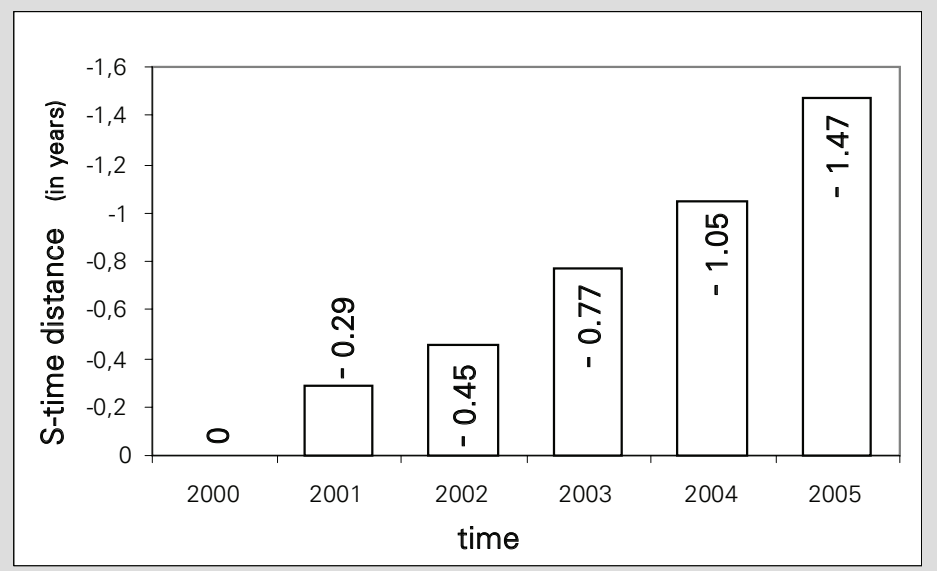

Legend: (-) time lead (ahead of the line to target); time lag (behind the line to target) Source: Eurostat; own calculations 


\section{Aleksander Aristovnik, Andrej Pungartnik Implementation of the Lisbon Strategy Targets at the Regional Level in the EU and Slovenia}

A slightly poorer situation was observed in the Eastern Slovenia region which in fact did record a time lead in the last two analysed years, yet a smaller one than in Western Slovenia. In view of the situation in the country, the results of the time distances for the targeted average annual growth rate of GDP at the NUTS 2 level in Slovenia were expectedly more favorable in the western area, which boasts better infrastructure, a highly qualified labor force and better development opportunities; this consequently means higher average economic growth and more favorable time distances.

Figure 8: Time distance of Eastern Slovenia in meeting the target of average $3 \%$ annual GDP growth

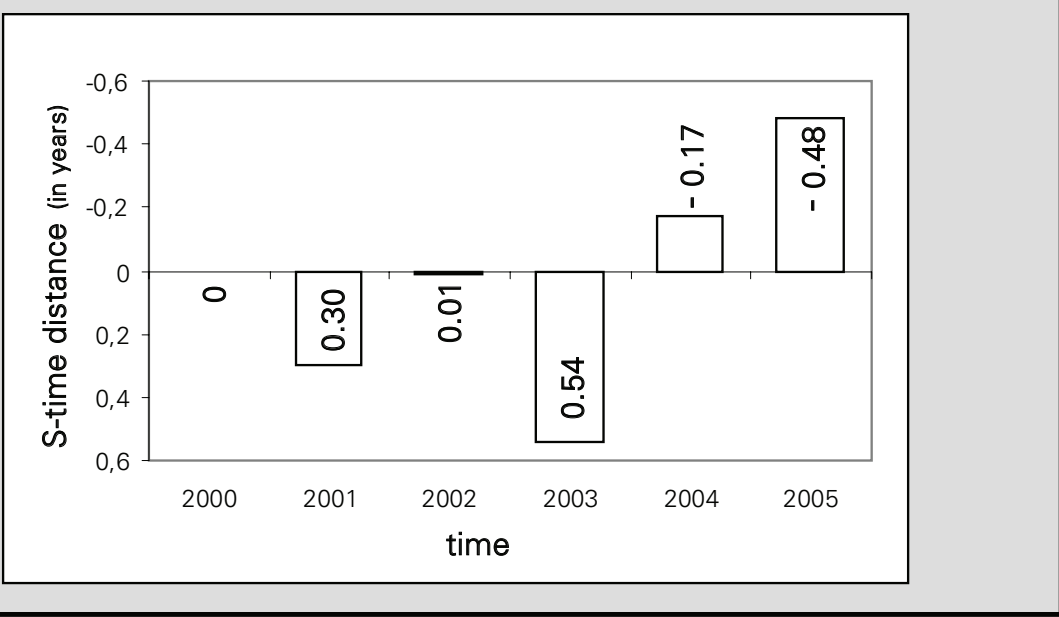

Legend: (-) time lead (ahead of the line to target); time lag (behind the line to target) Source: Eurostat; own calculations

It all seems that the results of the attainment of the targets at the level of Slovenia are better. As regards attainment of the target of a $70 \%$ employment rate by 2010, the time distance results are encouraging compared to the average time distances of the most and the least developed NUTS 2 EU regions. In 2006, the lag was 0.59 years. The latest data show that in 2007 the lag turned into a lead when the actual employment rate exceeded the targeted one, which put Slovenia well on the road to achieve or even exceed the $70 \%$ employment rate target in 2010. However, the global recession, the resulting slower economic growth and the increasing unemployment rate will greatly hinder the attainment of the targets or even make it impossible. As expected, Slovenia achieved a time lead in the target of average $3 \%$ annual growth as, 


\section{Aleksander Aristovnik, Andrej Pungartnik \\ Implementation of the Lisbon Strategy Targets at the Regional Level in the EU and Slovenia}

being an ambitious new member, it has to achieve high growth rates to approximate the most developed countries. However, the results of time distances are more favorable for Western than Eastern Slovenia.

\section{Conclusion}

Along with fast-track global development, technological progress and changes in the economy and the environment, development dynamics and competitiveness play increasingly important roles in the generation of economic growth. By adopting the Lisbon Strategy in 2000, the heads of government of EU member states set framework targets which the EU was to achieve in ten years', time to thus become the most competitive, dynamic and knowledge-based economy in the world, capable of generating sustainable economic growth, new and better-quality jobs and stronger social cohesion. Through the 2005 reform, the Union redefined the main targets and priorities and also recognised the cohesion policy as one of the major Community policies for implementing the strategy for growth and jobs. Concurrently with implementation of the strategy at the EU level, Slovenia started following this implementation in 2004 when it became a full member of the European Union. Given that the development challenges lying ahead of Slovenia strongly resemble the challenges of the EU as a whole, it is understandable that the targets set in the strategic documents of Slovenia are very similar to those of the EU.

To demonstrate the size of Slovenia's and the Union's lags behind the Lisbon Strategy targets, we used an application designed by the Socioeconomic Indicators Center which enables the calculation of time distances and deviations from the targets. Due to a lack of data at the regional level, the measurement of the time distance for individual indicators is impossible or very difficult. The analysis thus includes calculations of time distances for two Lisbon Strategy targets at the NUTS 2 region level, namely the target of a 70\% employment rate and the target of average 3\% annual GDP growth by the end of 2010 .

The finding derived from calculating time distances at the level of regions is that both the most and the least developed regions, together accounting for $10 \%$ of the EU population, lag behind the targeted values in meeting the $70 \%$ employment rate in the EU and an average 3\% annual growth rate of the EU's GDP. The exception is the least developed regions at the EU-27 level which 


\section{Aleksander Aristovnik, Andrej Pungartnik \\ Implementation of the Lisbon Strategy Targets at the Regional Level in the EU and Slovenia}

recorded a time lead in meeting the target of average annual GDP growth. However, this was expected as less developed regions must grow faster than the more developed ones to generate convergence and reduce the development gap. Based on the above, the time distance confirms the results pertaining to the effects of the cohesion policy at the level of regions where convergence between European regions and smaller discrepancies in regional development were established. At the level of Slovenia, the results on the attainment of the targets are more favorable, mainly in terms of employment, and according to the expectations Slovenia recorded a time lag in the target of average annual GDP growth, which applies to both regions at the NUTS 2 level. Nevertheless, the fact that the development gap between the Slovenian regions of Eastern and Western Slovenia does not decrease, raises concern and this means that an intensive cohesion investment in Eastern Slovenia will be required in the future.

The results of calculating the time distances thus roughly confirm the expectations that both the EU and Slovenia at the NUTS 2 level mainly lag behind the Lisbon targets, with the exception of the less developed regions in the attainment of the targeted average annual growth rate. It can be established that the Lisbon Strategy targets by 2010 will be achieved only with great difficulty as the lag is already too large - mainly in terms of employment. Moreover, attainment of the targets will further be hindered or even made impossible by the global recession and the consequent slower economic growth and higher unemployment. However, the fear of the economic crisis and resulting failure to attain the Union's targets must be substituted by even more decisive and concrete implementation of the Strategy as it is only in this way that the effects of the recession can be mitigated.

At the EU level, a stronger action plan should introduce short-term measures to ease the crisis and tailor the medium- and long-term measures of the Lisbon Strategy to help in the fight against the recession. The financial market must be stabilised, measures introduced to reduce the risk of a reoccurrence of the crisis and structural reforms pursued, mainly in areas which support innovations and promote productivity and thus help economies become more flexible and resistant. It is vital that implementation of the Strategy reinforces and that the path out of the crisis gives rise to an even more effective Strategy which can cope with the future challenges and seize the opportunities offered by globalisation. 


\section{Aleksander Aristovnik, Andrej Pungartnik \\ Implementation of the Lisbon Strategy Targets at the Regional Level in the EU and Slovenia}

Dr. Aleksander Aristovnik is currently working at the Faculty of Administration (University of Ljubljana) as an Assistant Professor in the Department of Public Sector Economics. His areas of research interest encompass Public Sector Economics, International Economics, International Finance and Economics of the EU. He has actively participated in more than thirty international conferences around the world and published many professional and scientific articles in various domestic and recognized international publications (e.g. Eastern European Economics, Journal of Economics, South-Eastern Europe Journal of Economics, etc.), recently. He is also a member of various international associations and organisations (e.g. European Economic Association, Regional Studies Association, (NFER).

Mag. Andrej Pungartnik is a Master of Economic Science. He finished his masters at the Faculty of Economics (University of Ljubljana) where he also completed his undergraduate study, specialising in marketing. During his study years he acquired extensive knowledge in the fields of regional development, territorial cooperation and European cohesion policy. Currently he is working in advertising. 


\section{Aleksander Aristovnik, Andrej Pungartnik Implementation of the Lisbon Strategy Targets at the Regional Level in the EU and Slovenia}

\section{Bibliography}

- Aplikacija SICENTER. (2008). Retrieved 1.7., 2009, from http://www.gaptimer.eu/s-td_monitoring_tool.html

- $\quad$ Center za socialne indikatorje - SICENTER. (2008). Retrieved 15.7., 2009, from http://www.sicenter.si/indexsi.html

- Eurostat (2008). Retrieved 25.7,.2009, from http://www.ec.europa.eu/eurostat/

- Granger C.W.J., Jeon Y. (1997). Measuring Lag Structure in Forecasting Models - The Introduction of Time Distance. (San Diego: University of California).

- Granger C.W.J., Jeon Y. (2003). A time-distance criterion for evaluating forecasting models. International Journal of Forecasting, Vol. 19.

- Jones, A. R. (2001). The Politics and Economics of the European Union. (2nd ed.) (Northampton: Edward Elgar).

- Kok, W. (2004). Facing the challenge. The Lisbon strategy for growth and employment. (Luxembourg: Office for Official Publications of the European Communities).

- Martín, C. (2001). European Integration and Income Convergence, Lessons for Central and Eastern European Countries. (Washington: The World Bank).

- Müller, K. H. (2004). Time and Societal Evolution: The Theoretical background for Time Distance Analysis. (Vienna: WISDOM).

- Nacionalni strateški referenčni okvir 2007-2013. (2007). (Ljubljana: Služba Vlade RS za lokalno samoupravo in regionalno politiko).

- Nov začetek za Lizbonsko strategijo. (2005). (Luksemburg: Urad za uradne publikacije Evropskih skupnosti).

- $\quad$ NUTS. Klasifikacija statističnih teritorialnih enot v Evropski Uniji - NUTS pojasnilo. (2008). Retrieved 15.7., 2009, from http://www.stat.si/tema_splosno_upravno_NUTS.asp

- Nacionalni strateški referenčni okvir 2007-2013. (2007). (Ljubljana: Služba Vlade RS za lokalno samoupravo in regionalno politiko).

- Nov začetek za Lizbonsko strategijo. (2005). (Luksemburg: Urad za uradne publikacije Evropskih skupnosti).

- Sicherl, P. (2003). Fleksibilnost dela - primerjalna analiza. (Ljubljana: Fakulteta za družbene vede). 
Aleksander Aristovnik, Andrej Pungartnik Implementation of the Lisbon Strategy Targets at the Regional Level in the EU and Slovenia

- Sicherl, P. (2008). Monitoring implementation of Lisbon and NRP targets with S-timedistance measure. (Ljubljana: SICENTER).

- $\quad$ Služba vlade RS za evropske zadeve. (2008). Retrieved 23.7., 2009, from http://www.svez.gov.si/si/aktualne_teme/lizbonska_strategija/

- $\quad$ Time-distance analysis: method and applications. (2004). (Vienna: WISDOM). 